enhance or suppress - depending on timing of administration and dosage of antibody - the responses of mice to hydroxynitrophenol (NP) ${ }^{4}$. Their very latest achievement is to have enhanced the idiotype-positive component of an antibody response to NP by injection of 10 $\mu \mathrm{g}$ of idiotype-bearing antibodies in advance of immunization with NP.

\section{The major histocompatibility complex}

If the T-cell receptor remains elusive, the MHC is about to yield up its mysteries to the inexorable advance of the DNAcloning army. So far, however, the process has only just started, the sequencing has barely begun, and the data largely confirm the existing biochemistry - though there may be some surprises for the geneticists.

MHC antigens, known as HLA antigens in man and $\mathrm{H}-2$ in mouse, are composed of two chains, the smaller of which, $\beta_{2}$ microglobulin, is relatively invariant. The structure of the protein chain shows considerable homology to the constant region of immunoglobulin, but a preliminary analysis of the human genomic DNA (J. Parnes, US National Institutes of Health) suggests that the distribution of introns may be more like that of the variable region.

The larger, $\alpha$ chain, which is highly polymorphic, has only more recently been recognized as having structural similarities to immunoglobulin ${ }^{5}$. Comparing amino acid sequences, J. Strominger (Harvard University) finds 35 per cent homology between the third domain of the $\alpha$ chain of HLA-A and the fourth domain of the immunoglobulin constant region. L. Hood (California Institute of Technology), who has used an HLA probe to identify the $\mathrm{H}-2$ genes, has sequenced the cDNA coding for the third $\alpha$ domain and finds 50 per cent homology with the DNA encoding the fourth constant-region domain of mouse IgM. Moreover, he infers from analysis of the 'wobble' positions of the codons, which have 45 per cent homology instead of the 25 per cent that would be expected by chance, that the homology is due to divergent rather than convergent evolution.

The most startling news came from the California Institute of Technology where, according to E. Moore, densitometric analysis of genomic bands from the $\mathrm{H}-2$ complex of the mouse suggest there may be 15 or so related genes 6 rather than the four or five predicted by the genetics. Similar data have since been reported by Cami et $a l^{7}$, and probably signify the existence of a multi-gene family possibly encoding lymphocyte differentiation antigens.

\footnotetext{
1. Jerne, N.K. Scient. Am. 52 (1973).

2. Eichmann, K. \& Rajewsky, K. Eur. J. Immun. 5, 661 (1975).

3. Robertson, M. Nalure, News and Views 290, 625 (1981).

4. Reth, M., Kelsoe, G. \& Rajewsky, K. Nature 290, 257 (1981)

5. Steinmetz, M. et al. Cell 24,125 (1981).

6. Cami, B., Brégégère, F., Abastado, J.P. \& Kourilsky, P. Nature (in the press).
}

This raises the question, posed by $\mathrm{L}$. Hood (California Institute of Technology), of how to identify the members of a multi-gene family without knowing what proteins they encode - a problem to which J. Sim (Columbia University) supplied the solution, at least for membrane proteins. She described a system for using cloned DNA to transform fibroblasts and for assaying the fibroblasts for new surface antigens with cytotoxic lymphocytes, or with antibodies - a technique she and her colleagues have used to identify a genomic clone containing an HLA antigen-encoding sequence.

Nothing in immunology is beyond the wit of man (or woman). T-cell receptor next.

\title{
Blood lead concentrations reconsidered
}

\section{from Philippe Grandjean}

Two recent studies of blood lead concentrations have provided evidence that, compared with the usual average of $10-20 \mu \mathrm{g}$ $\mathrm{dl}^{-1}$ found in Western Europe and North America, levels in remote societies are much lower. Poole and colleagues ${ }^{1}$ found a mean blood lead concentration of $5 \mu \mathrm{g} \mathrm{dl}^{-1}$ in 100 children from an unpolluted area in Papua New Guinea and Piomelli and coworkers ${ }^{2}$ established an average blood level of about $3 \mu \mathrm{g} \mathrm{dl}^{-1}$ in 103 Nepalese children and adults from the foothills of the Himalayas. The two investigations were carefully performed in order to avoid the contamination that has marred many lead assays in the past ${ }^{3}$. The results are supported by an earlier study of Venezuelan Indians ${ }^{4}$ which also indicated low blood lead concentration - below $1 \mu \mathrm{g}$ $\mathrm{dl}^{-1}$ - although the analytical techniques were perhaps subject to some doubt.

Atmospheric lead pollution spreads throughout the world so even population groups living in remote areas may be exposed to lead levels which are higher than natural, pre-industrial levels. One way in which natural levels can be assessed is by the analysis of prehistoric skeletal remains. Such samples, if uncontaminated, can be used to give accurate estimates, since lead accumulates in calcified tissues. Determination of lead in temporal bones and secondary dentine found in the sands of the Sahara has enabled lead levels in Sudanese Nubia to be assessed for the period from BC 3300 to AD 750 (ref.5). The results show that about 5,000 years ago, lead exposure at the Nile banks in Nubia was about one per cent of current exposures in Western Europe and North America. Later, during the Egyptian occupation and with the introduction of metallurgical techniques, tissue lead levels in Nubia increased considerably.

Further evidence comes from Ericson $e t$ al. ${ }^{6}$ who examined calcified tissues of a

Philippe Grandjean is in the Department of Occupational Medicine, Danish National Institute of Occupational Health. small number of Peruvian mummies. Using sophisticated analyses, they estimated that present-day lead exposures may have increased by about 500 -fold above pre-metallurgical levels in Peru.

A report from the US National Academy of Sciences (NAS) ${ }^{7}$ also carefully evaluates the natural occurrence of lead in the environment. Without doubt, lead was never uniformly distributed in the biosphere, and even in pre-industrial times a range of natural exposures would be expected. The NAS committee concludes that current exposure levels in industrialized countries are about 10 - to 1,000-fold above natural concentrations.

What is the significance of these figures for human health? Unfortunately, no clear answer is available. Although current background lead levels appear well above those which early man experienced, there is no definite evidence for the threshold at which lead begins to have a toxic effect. Most studies have examined effects at, say, concentrations of lead 1,000-10,000 times the natural level and compared them to a control group with a lead burden 100 -fold greater than that. However, toxic effects of lead are now being found at increasingly low levels and the most recent evidence ${ }^{8}$ suggests that they may be close to, or perhaps even below, current background levels.

Until proper studies of low-level lead toxicity, incorporating 'unpolluted' control groups, can be conducted, the recommendation of the NAS committee that "a serious effort should be made to reduce the baseline level of exposure to lead for general population of the United States" should be carefully considered in every industrialized country.

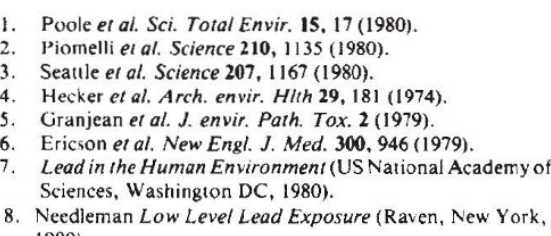

